\title{
Ophthalmic Doppler in persistent hyperplastic primary vitreous atypical presentation: case report
}

\author{
Doppler oftálmico na persistência hiperplásica do vítreo primário de apresentação atípica: relato de caso
}

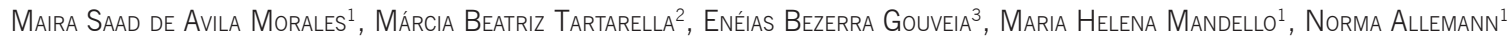

\begin{abstract}
The purpose is to document a case of persistent hiperplastic primary vitreous (PHPV) with atypical Bergmeister's papilla and patent hialoid artery that had its conclusive diagnosis done by doppler ultrasound. We report a case of child, who had unilateral leucokoria. This child's fundoscopic examination showed a white mass on the optic nerve that extended over to adjacent retina. Performed ultrasound that remained a doubt with the following diagnostic hypotheses: persistent hiperplastic primary vitreous, granuloma (toxocara), astrocytic hamartoma and retinoblastoma. The diagnosis was only established when the doppler ultrasound showed a blood flow inside of the membrane, thus confirming the diagnosis of persistent hiperplastic primary vitreous associated with the Bergmeister's papilla.
\end{abstract}

Keywords: Persistent hyperplastic primary vitreous/ultrasonography; Ultrasonography; Dopller; Toxocariasis; Retinoblastoma

\section{RESUMO}

Oobjetivoédocumentarum caso de persistência hiperplásica do vítreo primário (PHPV) com papila de Bergmeister atípica e artéria hialóide pérvia que teve seu diagnóstico conclusivo feito pelo exame ultrassonográfico com Doppler colorido. Relatamos um caso de uma criança com leucocoria unilateral, apresentando massa branca sobre o disco óptico observada à fundoscopia, que se estendia à retina adjacente. Após a realização do exame ultrassonográfico foi mantida a dúvida com as seguintes hipóteses diagnósticas: persistência hiperplásica do vítreo primário, granuloma (toxocaríase) e retinoblastoma. O diagnóstico foi estabelecido após a utilização do Doppler colorido que evidenciou fluxo sanguíneo no interior da membrana, confirmando o diagnóstico de persistência hiperplásica do vítreo primário associada à papila de Bergmeister.

Descritores: Vítreo primário hiperplásico persistente; Ultrassonografia; Toxocaríase; Doppler; Retinoblastoma

\section{INTRODUCTION}

Persistent hyperplastic primary vitreous (PHPV) is a vitreoretinal malformation characterized by defects in the primary vitreous regression ${ }^{(1)}$. It is a non-heritable disease ${ }^{(2)}$. Most cases are unilateral and sporadic, with no differences of incidence between males and females. It is the second most common cause of acquired cataract during the first year of life $\mathrm{e}^{(3)}$.

The hyaloid artery becomes impermeable to blood flow during the seventh month of pregnancy, until its complete regression during the following month ${ }^{(4)}$. Bergmeister's papilla arises from the primitive epithelial papillary cells. This papilla forms a glial sheath around the proximal one third of the hyaloid artery, which begins to atrophy during the seventh month of pregnancy. Failure of complete regression results in Bergmeister's papilla ${ }^{(4)}$.

PHPV is classified as anterior and posterior types, or a combination of both. Anterior PHPV is characterized by the presence of a retrolental membrane or mass (Mittendorf dot) and corresponds to $25 \%$ of cases. This type is caused by residual fetal anterior vascular system, located in the site of anastomosis of the hyaloid artery and tunica vasculosa lentis in a microphthalmic eye. Patients with anterior PHPV also present with early leukocoria due to the presence of retrolental membrane and cataract induced by this tissue ${ }^{(4)}$. Posterior PHPV contributes to $12 \%$ of cases and occurs due to incomplete regression of hyperplastic primary vitreous. It is characterized by the presence of a dense opaque membrane, which extends from the optic disc to the peripheral retina or retrolental region. Crystalline lens is typically transparent, but becomes opaque progressively. The combination of anterior and posterior PHPV contributes to $63 \%$ of cases $^{(4)}$.

\section{CASE REPORT}

An eight-month-old nursing female infant was referred for ultrasonography due to congenital leukocoria in the left eye. The child was born by full-term eutocic delivery and presented normal postnatal development.

Upon eye examination, unilateral leukocoria and mild vertical deviation were observed. Left eye indirect ophthalmoscopy revealed a white mass on the optic disc involving the posterior pole and a membrane that extended from this mass to the vitreous cavity (Figure 1). The contralateral eye presented no abnormalities.

Ultrasonography (US) examination performed in Quantel CineScan equipment using a $10 \mathrm{MHz}$ probe showed a solid elevated lesion on the optic disc. The lesion presented medium-high internal reflectivity and extended from the optic disk to the posterior pole, with internal acoustic shadowing from the papillary area up to the lesion apex, suggesting the presence of a vessel. Also, a medium-high reflective membrane was observed. This membrane was adherent to the lesion surface, extending into the vitreous cavity and limited into its pos-
Submitted for publication: July 31, 2014

Accepted for publication: January 15, 2015

Ultrasonography Service, Department of Ophthalmology and Visual Sciences, Paulista School of Medicine (EPM), Universidade Federal de São Paulo (UNIFESP), São Paulo, SP, Brazil.

Congenital Cataract Service, Department of Ophthalmology and Visual Sciences, Paulista School of Medicine (EPM), Universidade Federal de São Paulo (UNIFESP), São Paulo, SP, Brazil.

${ }^{3}$ Uveitis Service, Department of Ophthalmology and Visual Sciences, Paulista School of Medicine

(EPM), Universidade Federal de São Paulo (UNIFESP), São Paulo, SP, Brazil.
Funding: No specific financial support was available for this study.

Disclosure of potential conflicts of interest: None of the authors have any potential conflict of interest to disclose.

Corresponding author: Maira Saad de Ávila Morales. Rua Engenheiro Sá Rocha, 345 - São Paulo, SP - 05454-020 - Brazil -E-mail: mairamorales63@hotmail.com 
terior third, in all meridians. The adjacent vitreous was anechoic and there was no retinal detachment. The axial length was asymmetrical: right eye (RE) $21.5 \mathrm{~mm}$ and left eye (LE) $19.5 \mathrm{~mm}$ (Figure 2).

Color Doppler was performed in the Esaote My Lab 25 Gold equipment, with small parts linear probe. Results showed internal flow in the topography of the acoustic shadowing observed by conventional US, which extended to the membrane adhered to the lesion surface. These findings allowed us to reach a conclusion of PHPV diagnosis (Figure 3).

\section{DISCUSSION}

In this case, the infant presented leukocoria and small vertical deviation. Fundoscopic exam showed a white mass on the optical disc, which extended to the posterior pole. These findings suggested the following diagnostic hypotheses: PHPV associated with Bergmeister's papilla, granuloma (toxocariasis), astrocytic hamartoma, and retinoblastoma.

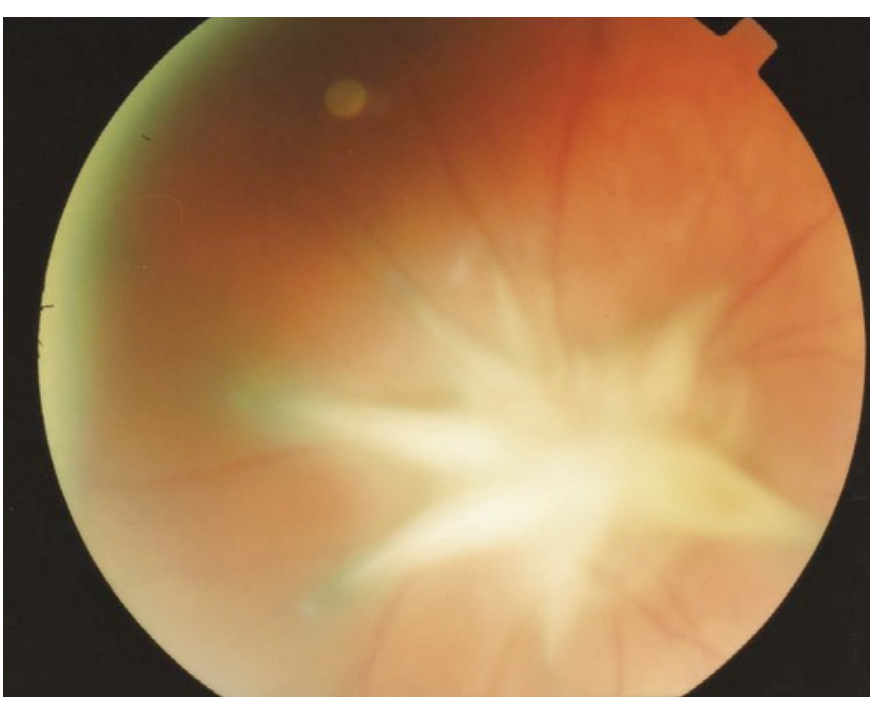

Figure 1. Left eye retinography showing a white mass on the optic nerve, which extend to the posterior pole and has a membrane adhered to it.

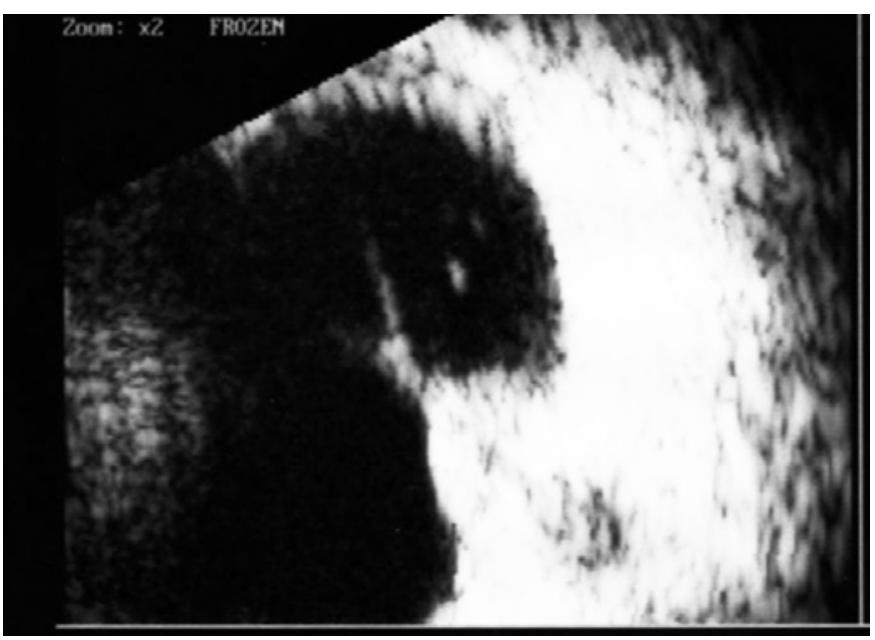

Figure 2. Left eye ultrasonography $(10 \mathrm{MHz})$, showing a solid elevated medium-high reflective lesion, which extends from the optic nerve to the posterior pole. This lesion presents inner acoustic shadowing. Also, a membrane echo adhered to the lesion and extending to the vitreous posterior third is observed.
Clinical criteria can be associated with additional tests in order to differentiate the causes of leukocoria. These criteria include: age, sex, involvement of one or both eyes, heredity, vitreous involvement, presence or absence of calcification, and eyeball size ${ }^{(5)}$

Based on these criteria, the leading causes of leukocoria were discarded. Since the child was born after a full-term pregnancy, we discarded retinopathy of prematurity. The absence of telangiectasia, white-yellow exudates, and exudative retinal detachment excluded Coats' disease hypothesis. Thereby, we considered the main previously mentioned hypotheses ${ }^{(3)}$.

The inconclusive cases, in which the clinical examination does not disclose the diagnosis, require the use of complementary exams, such as ultrasonography with or without associated color Doppler, computed tomography, and nuclear magnetic resonance imaging ${ }^{(1)}$

Although indirect ophthalmoscopy allowed the observation of a white solid mass with glial appearance involving the whole papilla and extending to the posterior pole, these findings were not sufficient for diagnostic disclosure. Thereby, we chose to perform further imaging exams.

Initially, we performed conventional ultrasonography (US), because it presents good sensitivity and specificity for diagnosis and localization, extent and characterization of intraocular and tumor lesions. Doppler ultrasonography (USD) allows the evaluation of vessel flow and can be used in the assessment of vascular lesions, intraocular tumors and orbital lesions, besides cases of membrane differentiation such as retinal detachment and posterior vitreous detachment with impregnated hyaloid(3,6-8)

Toxocariasis cases, upon US examination, present condensate hyperechoic shadows with medium-high reflective membrane extending from the lesion to the periphery. Calcifications, however, are uncommon ${ }^{(3)}$, and upon Doppler examination, there would be neither flow to the lesion (granuloma) nor to the membrane. Small retinoblastoma may not present calcification. The presence of internally calcified tumors in children younger than three years old, however, leads to a diagnosis of retinoblastoma. The lesion is usually localized in the posterior portion of the globe, extending into the vitreous (endophytic) or choroid (exophytic). Upon Doppler examination, internal vessels can be observed throughout the lesion. Astrocytic

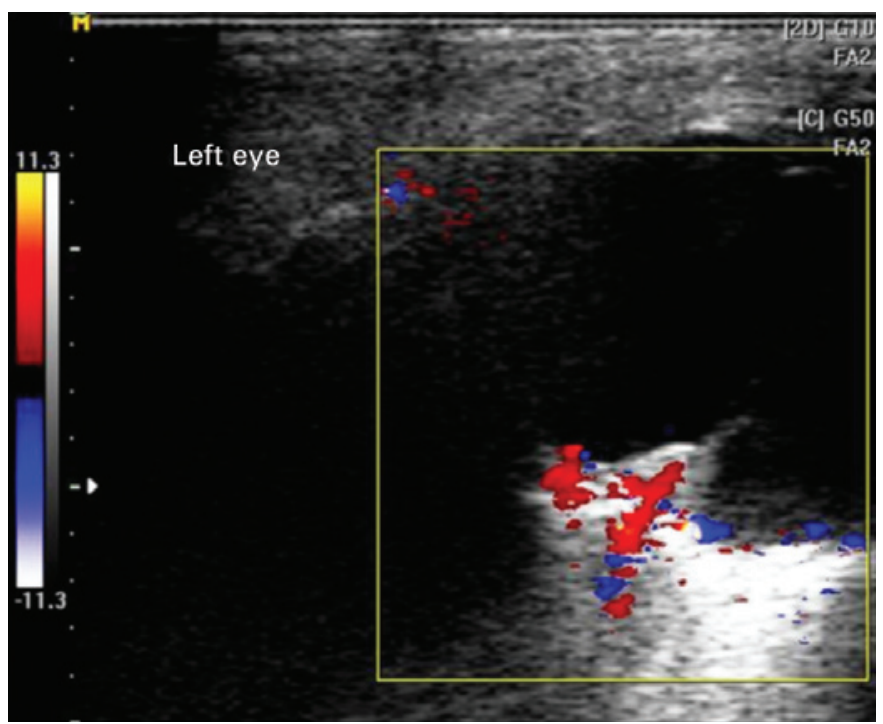

Figure 3. Left eye color Doppler ultrasonography (small parts linear probe) showing a solid lesion on the optic nerve with inner acoustic shadowing and an adhered membrane. The lesion presents arterial flow consistent with permeable hyaloid artery. 
hamartomas and retinal astrocytomas are rare neoplasms derived from retinal nerve fibers or, uncommonly, from the optic nerve. They represent almost 3\% of childhood leukocoria cases. Upon US examination, these lesions usually are highly reflective, often calcified and present posterior acoustic shadowing. In PHPV cases, highly reflective membrane shadows are observed on the papillary area, extending to the vitreous posterior third or to the crystalline posterior capsule (incomplete or complete form) ${ }^{(3)}$ and associated with reduced anteroposterior diameter. This report describes a non-typical case that includes the observation of a mass on the papillary area, extending to the posterior pole with a membrane adhered to the lesion ${ }^{(9)}$. These characteristics caused diagnostic uncertainty. US examination absence of internal calcifications on lesion and anechoic adjacent vitreous. Despite these results, the retinoblastoma hypothesis could still not be completely discarded ${ }^{(10)}$.

Color Doppler revealed a linear blood flow in the internal mass acoustic shadow, which extended to the membrane adherent to this mass. This linear blood flow corresponded to the permeable hyaloid artery. This finding led to the final PHPV diagnosis ${ }^{(6)}$ and adequate treatment was provided.

All diagnostic methods have their own limitations, reinforcing the importance of performing complementary exams. This will help reduce evaluation errors and consequently aid to adjust the conduct.

\section{ACKNOWLEDGEMENTS}

We acknowledge Dr. João Paulo Duprat for the retinography and Dr. Renata T. Kashiwabuchi for the help with literature surveys.

\section{REFERENCES}

1. Mafee MF, Goldberg MF. Persistent hyperplastic primary vitreous (PHPV): role of computed tomography and magnetic resonance. Radiol Clin North Am. 1987;25(4):683-92.

2. Goldberg MF. Persistent fetal vasculature (PFV): an integrated interpretation of signs and symptoms associated with persistent hyperplastic primary vitreous (PHPV). LIV Edward Jackson Memorial Lecture. Am J Ophthalmol. 1997:124(5):587-626.

3. Byrne SF, Green R L. Ultrasound of the eye and orbit. St. Louis: Contexto; 2002.

4. Pollard ZF. Persistent hyperplastic primary vitreous: diagnosis, treatment and results. Trans Am Ophthalmol Soc. 1997:95:487-549.

5. Silbert M, Gurwood AS. Persistent hyperplastic primary vitreous. Clin Eye Vis Care 2000;12(3-4):131-7.

6. Mihmanli I, Albayran MS, Kantarci F, Adalitli I, Islak C, Altug A. Persistent hyperplastic primary vitreous and von Hippel-Lindau disease: contributions of color Doppler ultrasonography. J Ultrasound Med. 2002;21(5):565-8.

7. Neroev WV, Kiseleva TN, Sudovskaia TV. [Complex ultrasound examination children with persisting hyperplastic primary vitreous].Vestn Oftalmol. 2011;127(4):24-8. Russian

8. Jain TP. Bilateral persistent hyperplastic primary vitreous. Indian J Ophthalmol. 2009; 57(1):53-4.

9. Awan JK, Humayun M. Changes in the contralateral eye in uncomplicated persistent hyperplastic primary vitreous in adults. Am J Ophthalmol. 1985;99(2):122-4.

10. Guthoff R. Echographic diagnosis of intraocular diseases. In: Guthoff R, editor. Ultrasound in ophthalmologic diagnosis. New York: Thieme Medical; 1991. p.61-74.

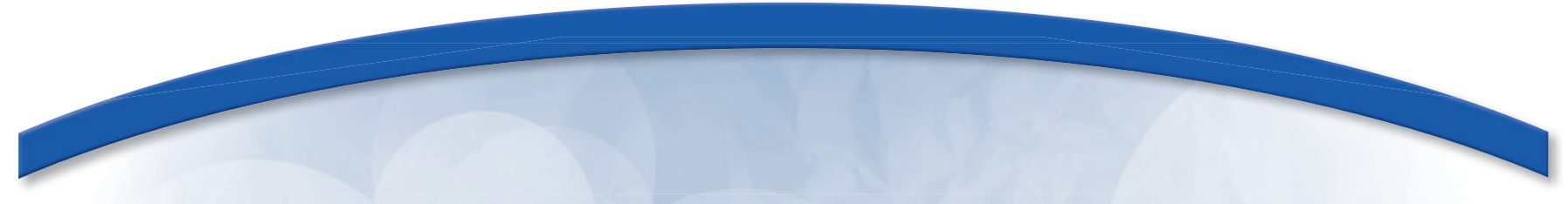

\title{
20 Congresso de Oftalmologia da Universidade Federal de Goiás
}

\author{
6 e 7 de novembro de 2015
}

Goiânia - GO

\section{Informações:}

E-mail: congressos@brturbo.com.br 